\title{
Evaluation of the effects of ketamine on spinal anesthesia with levobupivacaine or ropivacaine
}

\author{
YAN ZHANG ${ }^{1}$, HONG LIN ${ }^{2}$ and WEN-BO YI ${ }^{1}$ \\ ${ }^{1}$ Department of Anesthesiology, Qilu Hospital of Shandong University, Jinan, Shandong 250012; \\ ${ }^{2}$ Department of Anesthesiology, Qianfoshan Hospital of Shandong, Taian, Shandong 271000, P.R. China
}

Received March 14, 2015; Accepted April 21, 2016

DOI: $10.3892 /$ etm.2016.3587

\begin{abstract}
Spinal anesthesia or regional anesthesia is a potent anesthetic procedure. Additional modalities have been sought to increase the duration of block in spinal anesthesia. Ketamine is an N-methyl-D-aspartate (NMDA) receptor blocker that has an anesthetic effect when injected intrathecally and has a synergic effect with bupivacaine. Ketamine also has potent analgesic properties. The present study investigated the effect of intrathecally administered ketamine on spinal anesthesia with levobupivacaine or ropivacaine. Sprague-Dawley rats at post-natal day 21 were exposed to spinal anesthesia with $0.5 \%$ levobupivacaine or $0.5 \%$ ropivacaine. Separate groups of rats were treated with intrathecal ketamine at a 5 or $10 \mathrm{mg} / \mathrm{kg}$ bodyweight dose along with ropivacaine or levobupivacaine. The thermal and mechanical withdrawal latencies of the animals were determined using hot plate and von Frey filaments, respectively. A rotarod apparatus was employed to assess the capacity of the rats to rotate the spindle at $24 \mathrm{~h}$ following anesthesia. The gait of the rat pups was also assessed. Intrathecal administration of ketamine resulted in dense blocks and extended the duration of spinal blocks as evidenced by thermal latencies and responses to von Frey filaments. The latency to fall was shorter in rats exposed to ketamine along with ropivacaine or levobupivacaine spinal anesthesia. The gait parameters were also more disturbed upon ketamine administration. In conclusion, ketamine administration with ropivacaine or levobupivacaine increased the intensity and duration of spinal blockade, thereby increasing the anesthetic effects.
\end{abstract}

\section{Introduction}

Spinal anesthesia is a potent anesthetic procedure and is widely used as it has a number of advantages compared with general anesthesia, such as reduction of stress responses, reduced

Correspondence to: Dr Yan Zhang, Department of Anesthesiology, Qilu Hospital of Shandong University, 107 West Wenhua Road, Jinan, Shandong 250012, P.R. China

E-mail: zhangyan2112@gmail.com

Key words: anesthesia, ketamine, levobupivacaine, ropivacaine amount of blood loss, low cost and decreased morbidity and mortality rates in high-risk patients (1). It is used for both emergency and elective surgeries, and involves the injection of a local anesthetic agent into the cerebrospinal fluid, thereby blocking nerve transmission (2). Regional anesthesia has been suggested as an alternative to systemic anesthesia in order to evade or decrease general anesthetic exposure (3). In addition, spinal anesthetics have very short action times with infrequent complications such as shivering $(4,5)$. Several adjunct drugs have been added to spinal anesthetics due to concerns over toxicity and the duration of action $(6,7)$. Adjuncts such as benzodiazepines (8), opioids (9), neostigmine (10) and $\alpha 2$-receptor agonists $(11,12)$ have been employed.

Ketamine, an N-methyl-D-aspartate (NMDA) receptor blocker, has an anesthetic effect when injected intrathecally and is synergic with bupivacaine (13). Ketamine is a phencyclidine derivative with potent analgesic properties, which has various advantages over other local anesthetics, as it tends to stimulate the cardiovascular system and maintains respiratory response to carbon dioxide. Intrathecally administered ketamine is advantageous as its beneficial effects on the cardiovascular system and respiratory functions may be combined with the analgesic effects of spinal anesthesia (14). The primary mechanism of action of the spinal anesthetic ketamine is noncompetitive blocking of the NMDA ionophore.

Widespread use of bupivacaine for pain management has been largely based on the assumption that it is safe. Bupivacaine is a local anesthetic that is employed in nerve block, epidural and intrathecal anesthesia and is often administered to control pain prior to, during and following spinal surgery $(15,16)$. Although extensively used in pain control, bupivacaine has been reported to be cardiotoxic, neurotoxic and the most myotoxic of the local anesthetics (17).

Levobupivacaine and ropivacaine, new long-acting local anesthetics are S(-) enantiomers of two structurally similar molecules, 1-butyl-2',6'-pipecoloxylidide and 1-propyl-2',6'-pipecoloxylidide, respectively $(18,19)$ and are been developed as safer alternatives to bupivacaine. Though less lipid-soluble than bupivacaine, ropivacaine is a long-acting spinal anesthetic. Levobupivacaine exhibits similar efficacy to both ropivacaine and bupivacaine of sensory block for the sciatic nerve $(20,21)$, spinal block (22-24) and epidural block $(25,26)$, both in duration and intensity. Studies have demonstrated that levobupivacaine and ropivacaine are less neurotoxic than racemic bupivacaine, 
as evaluated by the production of seizures in rats $(27,28)$. With these considerations, the present study has been designed to evaluate the effects of intrathecal ketamine on spinal anesthesia with levobupivacaine or ropivacaine.

\section{Materials and methods}

Animals. This study was approved by the Institutional Animal Care Committee of Shandong University and performed in accordance with the National Institutes of Health Guide for the Use of Laboratory Animals (29). Female Sprague-Dawley rats (Guangdong Medical Laboratory Animal Center, Foshan, China) were used. A total of 70 rats were used that were housed in a room on a $12 \mathrm{~h}$ light/dark cycle with free access to water. Rats at post-natal day 21 (P21) were used for the study.

Injections of levobupivacaine and ropivacaine. The rats were anesthetized with isoflurane (3-5\%) in oxygen and air. Percutaneous intrathecal injections were administered at the low lumbar level (intervertebral space L4-5 or L5-L6) with a 30-gauge needle perpendicular to the skin. Injection volumes of $0.5 \mu \mathrm{l} / \mathrm{g}$ bodyweight, previously determined to produce spread across lumbar and low thoracic segments in rat pups (30), were delivered using a 50- $\mu 1$ Hamilton syringe with a $22 \mathrm{~s}$ ga gauge needle (Sigma-Aldrich, St. Louis, MO, USA). A $0.5 \%$ concentration of levobupivacaine (31) or ropivacaine $(32,33)$ was administered to the rats. Ketamine was administered at 5 or $10 \mathrm{mg} / \mathrm{kg}$ (34). Control rats received no anesthesia. The rats in the treatment groups received levobupivacaine or ropivacaine alone, ketamine (5 or $10 \mathrm{mg} / \mathrm{kg}$ ) and levobupivacaine, or ketamine ( 5 or $10 \mathrm{mg} / \mathrm{kg}$ ) and ropivacaine. A total of 10 rats were used in each group.

Behavioral assessments for sensory and motor blockade. The P21 rats underwent baseline measurement of hind paw thermal withdrawal latencies immediately prior to spinal injection. Blockade of thermal nociception was assessed using a modified hot plate test as described previously $(35,36)$. Hind paws were exposed (left then right) to a hot plate (model 39D hot plate analgesia meter; IITC Inc., Woodland Hills, CA, USA) at $53 \pm 1^{\circ} \mathrm{C}$. The time (thermal withdrawal latency) until the rats lifted their paws was measured using a stop clock. After 12-13 sec, the tested paw was removed to avoid injury to the animal or the development of hyperalgesia. The test was repeated thrice (with a 10-sec interval between tests) for each rat at every time point. Thermal withdrawal latencies were measured every $10 \mathrm{~min}$ for $\geq 60$ min after the intrathecal injections.

Blockade of mechanical nociception was also assessed in rats following exposure to anesthesia. Mechanical blockade was determined using hind paw withdrawal with the aid of von Frey filaments, used to apply logarithmically increasing pressure. The P21 rats were lightly restrained on a flat surface and a well-calibrated von Frey hairs device (Ugo Basile Electronic von Frey device; Stoelting Co., Wood Dale, IL, USA) that delivers increasing mechanical stimuli was applied to the dorsal surface of the hindpaw of each rat, five times with 1-sec intervals (37). The number of evoked withdrawal responses to each stimulus of increasing intensity was recorded until a given stimulus evoked five responses, or a suprathreshold cut-off pressure was reached (37). Mechanical withdrawal thresholds were recorded at baseline and every $10 \mathrm{~min}$ for $\geq 60 \mathrm{~min}$ after the intrathecal injection. Furthermore, for thermal and mechanical withdrawal tests, the rats were observed for the possibility of exhibiting motor blockade without sensory blockade, that is, by absence of lower limb movement accompanied by vocalization or signs of upper body escape responses. However, this was not observed.

The motor performance of the lower extremities was assessed by a qualitative pinch score. For each leg, if there was no spontaneous or evoked movement, the contribution to the score was zero. If there was partial movement, the contribution was one and if there was normal movement, the contribution to the score was two. Thus, in summing the values for the two legs, the score could range from zero (complete blockade) to four (normal).

Motor behavior on P22. Motor impairment of the rats that had undergone spinal levobupivacaine or ropivacaine and/or ketamine injections on P21 was assessed on P22. These rats were introduced to a dual species Economex Rotarod (Columbus Instruments, Columbus, OH, USA) using a spindle rotating at $10 \mathrm{rpm}$ (38). Each rat was tested thrice. A time interval of $10 \mathrm{~min}$ was used between each assessment. The maximal latency for each trial was $300 \mathrm{sec}$ before removal from the spindle. The average of the three assessments was used for data analysis.

Gait analysis at P23. In separate experiments, gait analysis was performed to determine the gait of the rats. The analysis was conducted on P23 following intrathecal injection on P21. Gait analysis was performed as the animal crossed the glass runway of the CatWalk system (Noldus Information Technology, Wageningen, The Netherlands) where the paw print area (surface area of floor contacted by hindpaw) and the paw print intensity (intensity of pixels forming area of paw contact) was measured. The regularity index (index for degree of interlimb coordination during gait), stability of gait (distance between two hindpaws measured perpendicular to walking direction), stride length (distance between placement of hindpaw and subsequent placement of same paw) and the duty cycle (ratio between stance duration and full stepcycle duration) was also measured. Animals underwent a daily training paradigm for 2 days on P22-23, with runway crossings toward food rewards at the distant end. On P23, runway crossings were recorded and included in analysis if the maximal time for crossing the $60 \mathrm{~cm}$ long section of the runway used for gait recording was $\leq 2 \mathrm{sec}$ and there were no intermediate stops during the crossing. Three crossings per animal were analyzed using CatWalk ${ }^{\circledR} 7.1 .6$ software (Noldus Information Technology).

Statistical analysis. All the values are represented as the mean \pm standard deviation. One-way analysis of variance was used and the values were analyzed using SPSS software version 17.0 (SPSS, Inc., Chicago, IL, USA). P<0.05 was considered to indicate a statistically significant difference.

\section{Results}

Response to thermal stimulus. Hind paw thermal withdrawal latencies were determined on P21 for rats in the groups 


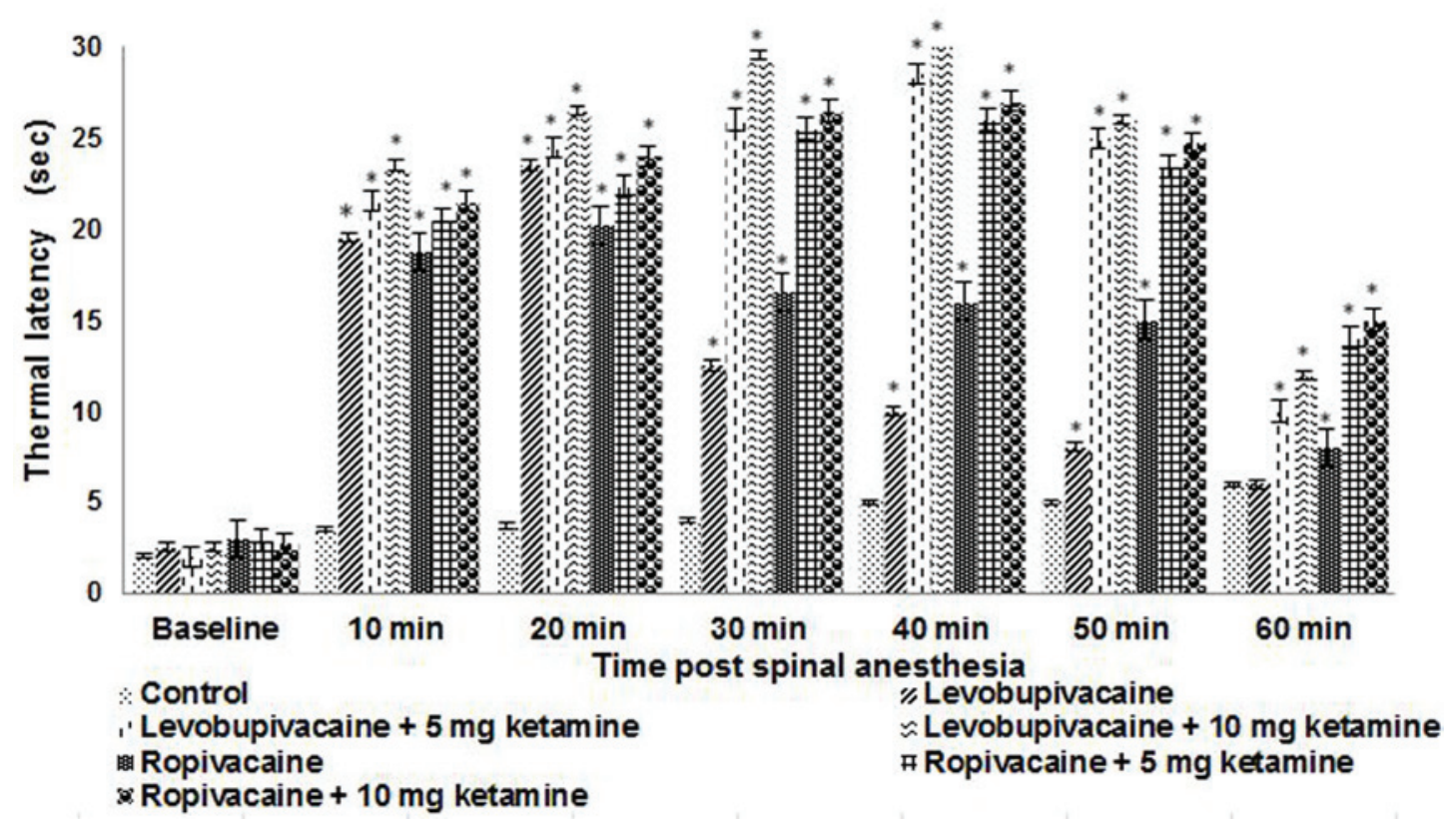

Figure 1. Thermal latency of P21 rat pups following spinal anesthesia. Values are presented as mean \pm standard deviation $(\mathrm{n}=6)$. ${ }^{*} \mathrm{P}<0.05$ vs. control as determined by one-way analysis of variance. P21, post-natal day 21 .

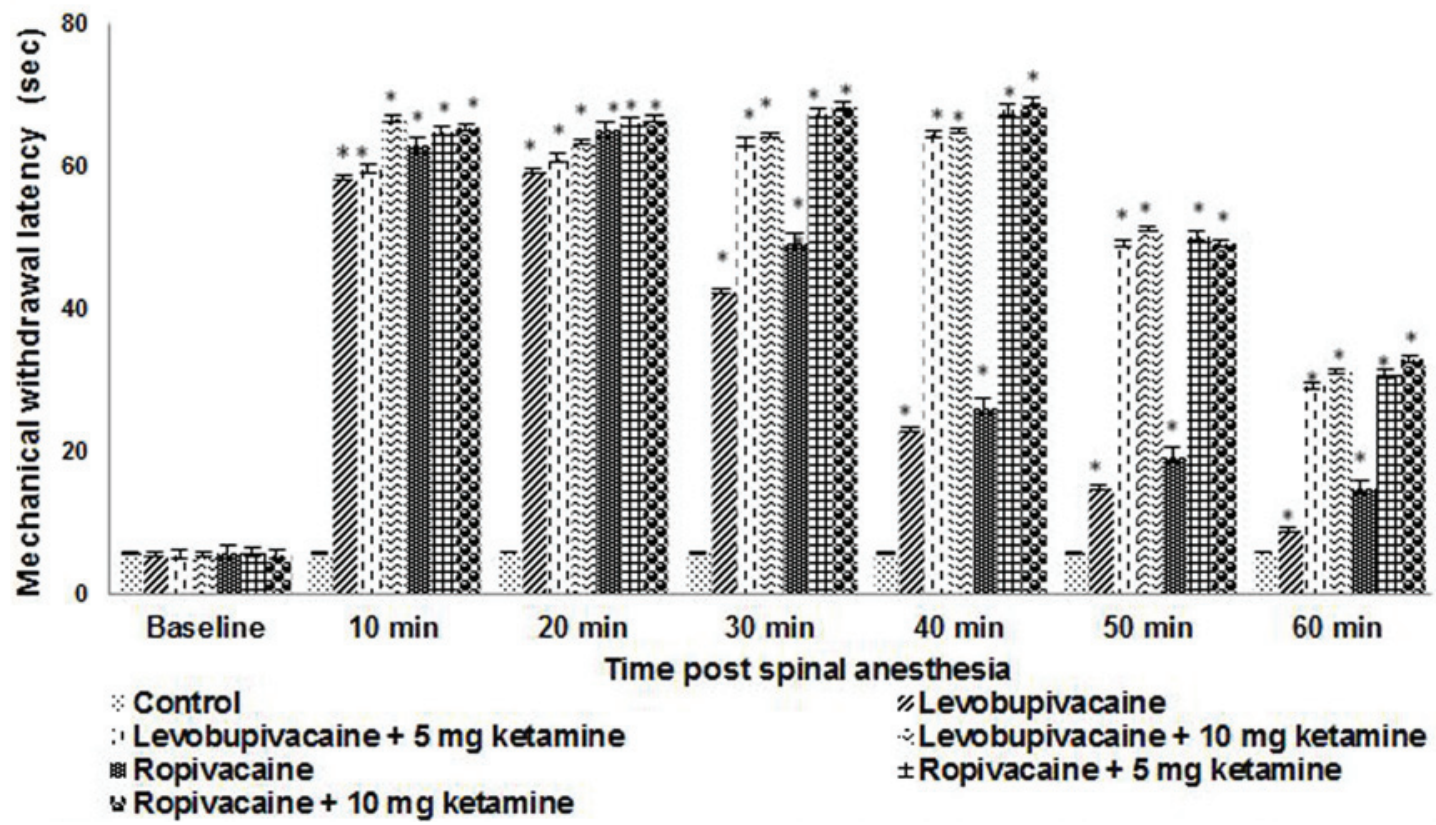

Figure 2. Mechanical withdrawal threshold of P21 rat pups following spinal anesthesia Values are represented as mean \pm standard deviation ( $\mathrm{n}=6$ ). ${ }^{*} \mathrm{P}<0.05 \mathrm{vs}$. control as determined by one-way analysis of variance. P21, post-natal day 21 .

receiving spinal anesthesia (Fig. 1). Levobupivacaine and ropivacaine produced dense thermal nociceptive blockade at the first measurement at 10 min following injection compared with control and remained dense at $20 \mathrm{~min}$. The co-administration of ketamine was found to further enhance the blockade to $40-45 \mathrm{~min}$, with a peak observed at $\sim 40 \mathrm{~min}$. The thermal withdrawal latencies remained significantly greater than control values at $50 \mathrm{~min}$ for the animals that received ketamine plus either ropivacaine or levobupivacaine; however, thermal withdrawal latencies remained higher and for a longer time for ropivacaine than for bupivacaine, irrespective of whether ketamine was co-administered (Fig. 1). The latencies were observed to be markedly higher and of longer duration in the rats that received a $10-\mathrm{mg}$ dose of ketamine with levobupivacaine or ropivacaine compared with rat pups that received 5 mg ketamine.

Response to mechanical stimulus. Mechanical withdrawal responses to von Frey filaments are presented in Fig. 2 for rats at P21 that received spinal anesthesia. Threshold values were higher following intrathecal injections compared with control. Thresholds were maximized between 5 to 40 min following 
Table I. Hind leg motor response of rats assessed using pinch scores following spinal anesthesia.

Time (min)

\begin{tabular}{|c|c|c|c|c|c|c|c|}
\hline \multirow[b]{2}{*}{ Group } & & & & & & & \\
\hline & 0 & 5 & 10 & 20 & 30 & 40 & 50 \\
\hline Control & 4 & 4 & 4 & 4 & 4 & 4 & 4 \\
\hline Levobupivacaine & 0 & 0 & 0 & 2 & 2 & 4 & 4 \\
\hline Levobupivacaine $+5 \mathrm{mg}$ ketamine & 0 & 0 & 0 & 1 & 2 & 2 & 4 \\
\hline Levobupivacaine $+10 \mathrm{mg}$ ketamine & 0 & 0 & 0 & 1 & 1 & 2 & 2 \\
\hline Ropivacaine & 0 & 0 & 0 & 0 & 2 & 2 & 4 \\
\hline Ropivacaine $+5 \mathrm{mg}$ ketamine & 0 & 0 & 0 & 0 & 1 & 1 & 2 \\
\hline Ropivacaine $+10 \mathrm{mg}$ ketamine & 0 & 0 & 0 & 0 & 1 & 1 & 2 \\
\hline
\end{tabular}

Values presented are mean scores $(n=6)$ on a scale where 0 indicates complete blockade and 4 indicates normal.

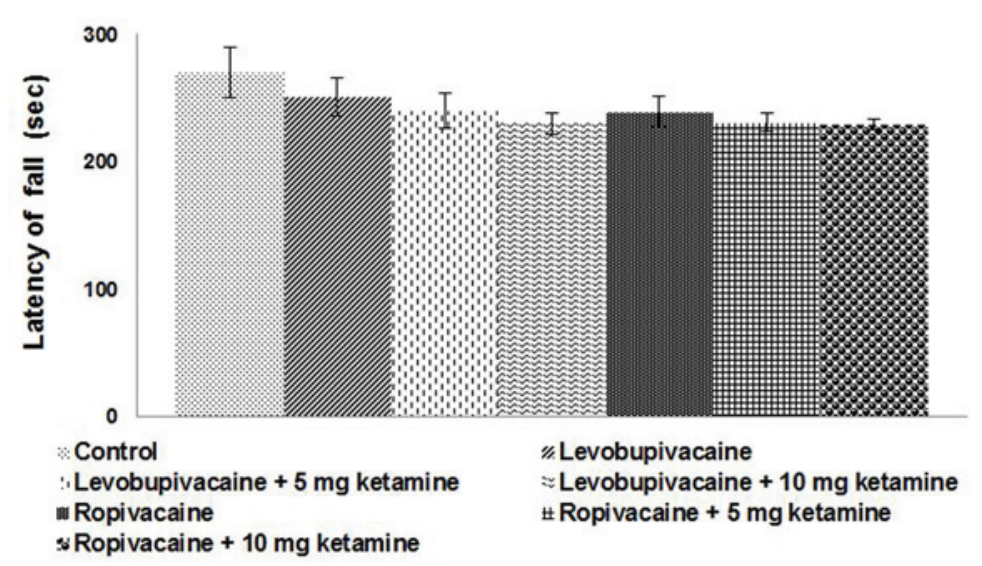

Figure 3. Latency of falling of rat pups following spinal anesthesia on P21. Values are presented as mean \pm standard deviation (n=6). P21, post-natal day 21 .

injections in rats receiving ropivacaine or levobupivacaine. In the rats that received ketamine along with ropivacaine, the threshold remained higher at $40 \mathrm{~min}$ as compared with that in rats exposed to ropivacaine alone. The $10 \mathrm{mg}$ dose of ketamine exhibited a higher mechanical blockade even at 50 min compared with the 5-mg dose, with fading of the effect from $40 \mathrm{~min}$. The combination of ketamine and ropivacaine resulted in blocks of longer duration as compared with levobupivacaine, which exhibited more dense blocks.

Motor block scores. Motor block (pinch) scores are shown in Table I. Rats at P21 that received either ropivacaine or levobupivacaine showed no signs of motor impairment. Levobupivacaine and ropivacaine produced dense motor block in all animals, which recovered almost completely by $40 \mathrm{~min}$ in all animals. Animals that received intrathecal injections of ketamine presented blocks even at $50 \mathrm{~min}$. At $40 \mathrm{~min}$, rats that received $10 \mathrm{mg}$ ketamine exhibited motor blocks more than those that received $5 \mathrm{mg}$ ketamine (Table I).

All control animals that received no anesthesia responded to pinching with forceps on the skin of the back with startled jerks and exhibited substantial escape behaviors. All animals that received spinal injections of levobupivacaine or ropivacaine did not exhibit behavioral response to pinching over the skin of the back at the lumbar and lower thoracic levels (between 8-10 min after injection); however, they showed slight withdrawal behaviors to pinching at upper thoracic levels and on the forepaws at 15-20 min after injections. Withdrawal behaviors were absent for a longer period of time in animals that received ketamine and ropivacaine compared with animals that received levobupivacaine and ketamine.

Motor performance in adult rats with postnatal anesthetic exposures. $\mathrm{P} 22$ rats that were exposed to intrathecal injections on P21 were tested for motor performance using a rotarod apparatus. Notable differences were observed in rats that received anesthesia as compared with control rats that were not exposed to anesthesia. Rats that received either ropivacaine or levobupivacaine along with ketamine exhibited falls at a much higher frequency and with shorter time intervals between the falls (Fig. 3). Ketamine injections resulted in shorter falling latency than that of the rats that received levobupivacaine or ropivacaine alone.

Gait analysis at P23. Gait analysis was performed on the rat pups on P23 following anesthesia exposure on P21. The influence of the anesthetics on the walking gait of the rat pups was analyzed using the CatWalk ${ }^{\circledR}$ runway system. The system recorded static and dynamic parameters, including paw pressure, print area, duty cycle (ratio between stance 
Table II. Gait analysis of rats following spinal anesthesia.

\begin{tabular}{|c|c|c|c|c|c|c|}
\hline \multirow[b]{2}{*}{ Group } & \multicolumn{2}{|c|}{ Static parameters } & \multicolumn{4}{|c|}{ Dynamic parameters } \\
\hline & $\begin{array}{l}\text { Paw print } \\
\text { area }\end{array}$ & $\begin{array}{l}\text { Paw print } \\
\text { intensity }\end{array}$ & $\begin{array}{l}\text { Regulatory } \\
\text { index }\end{array}$ & $\begin{array}{l}\text { Duty } \\
\text { cycle }\end{array}$ & $\begin{array}{l}\text { Stride } \\
\text { length }\end{array}$ & $\begin{array}{l}\text { Stability } \\
\text { of gait }\end{array}$ \\
\hline Control & $44.13 \pm 1.21$ & $171.20 \pm 10.20$ & $100.30 \pm 2.16$ & $60.16 \pm 1.14$ & $110.33 \pm 9.36$ & $34.19 \pm 0.77$ \\
\hline Levobupivacaine & $22.25 \pm 1.68^{\mathrm{a}}$ & $121.25 \pm 7.15^{\mathrm{a}}$ & $90.38 \pm 1.69^{\mathrm{a}}$ & $53.35 \pm 2.18^{\mathrm{a}}$ & $100.10 \pm 6.10^{\mathrm{a}}$ & $28.22 \pm 1.56^{\mathrm{a}}$ \\
\hline Levobupivacaine $+5 \mathrm{mg}$ ketamine & $18.50 \pm 1.22^{\mathrm{a}}$ & $118.80 \pm 9.21^{\mathrm{a}}$ & $88.11 \pm 2.53^{\mathrm{a}}$ & $51.20 \pm 2.05^{\mathrm{a}}$ & $95.16 \pm 4.81^{\mathrm{a}}$ & $20.15 \pm 1.00^{\mathrm{a}}$ \\
\hline Levobupivacaine $+10 \mathrm{mg}$ ketamine & $15.10 \pm 1.56^{\mathrm{a}}$ & $110.10 \pm 6.01^{\mathrm{a}}$ & $85.22 \pm 4.37^{\mathrm{a}}$ & $46.75 \pm 2.10^{\mathrm{a}}$ & $90.25 \pm 5.05^{\mathrm{a}}$ & $19.80 \pm 0.87^{\mathrm{a}}$ \\
\hline Ropivacaine & $21.20 \pm 0.54^{\mathrm{a}}$ & $123.56 \pm 5.96^{\mathrm{a}}$ & $89.21 \pm 4.16^{\mathrm{a}}$ & $53.44 \pm 1.36^{\mathrm{a}}$ & $102.21 \pm 3.74^{\mathrm{a}}$ & $27.80 \pm 0.54^{\mathrm{a}}$ \\
\hline Ropivacaine $+5 \mathrm{mg}$ ketamine & $17.51 \pm 0.66^{\mathrm{a}}$ & $119.56 \pm 5.07^{\mathrm{a}}$ & $87.20 \pm 2.90^{\mathrm{a}}$ & $50.23 \pm 2.22^{\mathrm{a}}$ & $93.25 \pm 2.90^{\mathrm{a}}$ & $24.10 \pm 1.36^{\mathrm{a}}$ \\
\hline Ropivacaine +10 mg ketamine & $14.88 \pm 0.60^{\mathrm{a}}$ & $113.24 \pm 4.29^{\mathrm{a}}$ & $81.06 \pm 5.06^{\mathrm{a}}$ & $48.68 \pm 3.12^{\mathrm{a}}$ & $90.20 \pm 4.60^{\mathrm{a}}$ & $20.05 \pm 1.01^{\mathrm{a}}$ \\
\hline
\end{tabular}

Values are presented as mean \pm standard deviation $(n=6)$. ${ }^{\mathrm{P}}<0.05$ vs. control as determined by one-way analysis of variance. Regulatory index, index for degree of interlimb coordination during gait.

duration and full step cycle duration), stride length as well as interlimb coordination. Ketamine injections at P21 resulted in a significant $(\mathrm{P}<0.05)$ reduction in paw print area and paw print intensity in rats that were exposed to spinal anesthesia with ropivacaine and levobupivacaine as compared with the intensities in control rats that were not exposed to anesthetics. The reduction in dynamic parameters was observed to be more marked in rats that received ketamine along with levobupivacaine or ropivacaine compared with those that received the latter two anesthetics without ketamine. More pronounced alterations in gait were observed in rat pups injected with the $10 \mathrm{mg}$ ketamine dose as compared with $5 \mathrm{mg}$ (Table II). The treatment with intrathecal injections of ketamine plus ropivacaine or levobupivacaine resulted in a greater anesthetic effect than ropivacaine or levobupivacaine alone.

\section{Discussion}

Local anesthetics and spinal analgesics are commonly co-administered to improve analgesia or reduce local anesthetic requirements $(34,39)$. The use of the stereoisomers levobupivacaine or ropivacaine, which have wider therapeutic windows than racemic bupivacaine, is increasing $(40,41)$. However, to prolong the duration of action, additional modalities are being sought. Ketamine is reported to act as an antagonist of the NMDA receptor in the spinal cord, and also to affect voltage-sensitive calcium channels, and opiate and monoaminergic receptors and thereby causes analgesic and anesthetic effects (42). Thus, the effect of ketamine is considered to be synergic with that of intrathecal bupivacaine because combined administration demonstrates better blocking with a longer duration $(13,29)$.

Several in vitro and in vivo studies have demonstrated the potential of ketamine for producing neuroprotective effects (43-45). This ability is indicated by the observations that ketamine blocks NMDA-receptor activation, mediates beneficial changes in apoptosis-regulating proteins and interferes with the inflammatory response to injury when administered in typical sedative or anesthetic doses. Cardiovascular stimulation caused by ketamine may also improve cerebral perfusion and this action may be advantageous in patients, particularly after brain injury (46).

Considering the effects of ketamine, the present study probed whether intrathecal ketamine increases the blockade induced by spinal levobupivacaine and ropivacaine. One of the most important properties of a long-acting local anesthetic is the reversible inhibition of nerve impulses, causing a prolonged sensory or motor blockade appropriate for anesthesia in different types of surgeries (47).

In the present study it was observed that a single dose of intrathecal levobupivacaine and ropivacaine at $0.5 \%$ produced reliable sensory and motor blockade in rat pups at P21. The results of the assessment of sensory and motor blockade in rat pups suggest that ropivacaine induced sensory and motor blocks for a longer duration than levobupivacaine. Administration of ketamine following levobupivacaine or ropivacaine resulted in stronger blocks and extended the duration of the blocks as determined using thermal and mechanical stimuli.

On further analysis of the extent of blockade, the performance of the rats following $24 \mathrm{~h}$ of anesthesia was determined using a rotarod apparatus. The latency to fall was recorded as the efficiency of the rats in rotating the spindle. The rats exposed to anesthesia presented a shorter period before falling, with the rats that received ketamine falling much sooner. The results of rotation of the spindle indicate that ketamine brought about stronger blockade than either ropivacaine or levobupivacaine administered as a single drug.

Earlier reports have demonstrated longer anesthetic blocks in patients receiving ketamine administration along with bupivacaine (42). Patients undergoing cesarean section who received intrathecal ketamine along with bupivacaine had a significantly prolonged duration of anesthesia compared with the control group of patients who received bupivacaine without ketamine (48).

Clinically, ketamine is administered via intravenous, intramuscular, epidural, intrathecal, rectal, subcutaneous, transdermal, topical, oral, intranasal, transmucosal and sublingual routes. Epidural ketamine has been reported to provide prolonged analgesia when administered alone or added to local anesthetics (49-51). Epidural injection has an additional benefit 
as inadvertent intravascular administration does not result in cardiovascular side effects (52) and intrathecal ketamine at doses of 3-10 $\mathrm{mg} / \mathrm{kg}$ exhibits dose-dependent antihyperalgesic effects in neonatal rats (34).

Gait analysis normally presents the stability of the rats following anesthesia. The gait analysis of the experimental animals was assessed using the CatWalk ${ }^{\circledR}$ system, which is a video-based automated gait analysis system that evaluates the changes in gait of rodents (53). The CatWalk ${ }^{\circledR}$ system allows analysis of sensorimotor co-ordination and both static and dynamic components of gait. Intrathecal ketamine injection resulted in alterations in the gait parameters in rats that were exposed to levobupivacaine or ropivacaine.

Marked reductions in hindpaw print area and print intensity were observed subsequent to ketamine administration. Duty cycle was observed to decrease, as the time that the hind paw was in contact with the surface during gait decreased. The results for dynamic parameters such as stride length, gait regularity and stability suggested that gait coordination was slightly decreased in the levopubivacaine and ropivacaine groups compared with that in the control rat pups. The changes in static and dynamic parameters were more pronounced in rats that received $10 \mathrm{mg}$ ketamine than in the rats that received the lower dose.

The results of the present study suggest that ketamine at doses of 5 and $10 \mathrm{mg} / \mathrm{kg}$ was effective in extending the anesthetic effects of ropivacaine and levobupivacaine. Kim et al (54) demonstrated the synergistic effects of intravenous ketamine administration in patients exposed to spinal bupivacaine. Prophylactic use of intravenous ketamine has been found to significantly reduce the frequency and the intensity of perioperative shivering associated with spinal anesthesia (55). Intraarticular ketamine and levobupivacaine when administered to patients undergoing arthroscopic meniscectomy provided more effective post-operative analgesia than ketamine alone (56).

The present study was conducted in an attempt to evaluate the anesthetic effects of ketamine when used in combination with ropivacaine or levobupivacaine. The observations are suggestive of the potency of ketamine in extending the duration and strength of spinal anesthesia. Furthermore, additional research is necessary in order to fully understand the effects of ketamine administration in combination with ropivacaine or levobupivacaine.

\section{Acknowledgements}

This study was supported by Shandong Province Science and Technology Agency funded projects (no. ZR2009CM098).

\section{References}

1. Gaiser RR: Spinal, epidural and caudal anesthesia. In: Introduction to Anesthesia. Longnecker DE and Murphy FL (eds). 9th edition. W.B. Saunders, Philadelphia, PA, pp230-231, 1997.

2. Charles BB: Local anesthetics. In: Miller's Anesthesia. Miller RD, Fleisher LA, Savarese JJ, Wiener-Kronish J and Young WL (eds). 6th edition. Elsevier/Churchill Livingstone, Philadelphia, PA, pp573-604, 2005.

3. McGowan FX Jr and Davis PJ: Anesthetic-related neurotoxicity in the developing infant: Of mice, rats, monkeys and possibly, humans. Anesth Analg 106: 1599-1602, 2008.

4. Sessler DI and Ponte J: Shivering during epidural anaesthesia. Anesthesiology 72: 816-821, 1990 .
5. De Whitte J and Sessler DI: Perioperative shivering: Physiology and pharmacology. Anaesthesiology 96: 467-484, 2002.

6. Sakura S, Kirihara Y, Muguruma T, Kishimoto T and Saito Y: The comparative neurotoxicity of intrathecal lidocaine and bupivacaine in rats. Anesth Analg 101: 541-547, 2005.

7. Sakura S: Research on local anesthetic neurotoxicity using intrathecal and epidural rat models. J Anesth 21: 533-544, 2007.

8. Bharti N, Madan R, Mohanty P and Kaul HL: Intrathecal midazolam added to bupivacaine improves the duration and quality of spinal anaesthesia. Acta Anaesthesiol Scand 47: 1101-1105, 2003.

9. Karaman S, Kocabas S, Uyar M, Hayzaran S and Firat V: The effects of sufentanil or morphine added to hyperbaric bupivacaine in spinal anaesthesia for caesarean section. Eur J Anaesthesiol 23: 285-291, 2006.

10. Tan PH, Chia YY, Lo Y, Liu K, Yang LC and Lee TH: Intrathecal bupivacaine with morphine or neostigmine for postoperative analgesia after total knee replacement surgery. Can J Anesth 48: 551-556, 2001.

11. Kanazi GE, Aouad MT, Jabbour-Khoury SI, Al Jazzar MD, Alameddine MM, Al-Yaman R, Bulbul M and Baraka AS: Effect of low dose dexmedetomidine or clonidine on the characteristics of bupivacaine spinal block. Acta Anaesthesiol Scand 50: 222-227, 2006

12. Yoshitomi T, Kohjitani A, Maeda S, Higuchi H, Shimada M and Miyawaki T: Dexmedetomidine enhances the local anesthetic action of lidocaine via an -2A adrsenoceptor. Anesth Analges 107: 96-101, 2008.

13. Togal T, Demirbilek S, Koroglu A, Yapici E and Ersoy O: Effects of $S(+)$ ketamine added to bupivacaine for spinal anaesthesia for prostate surgery in elderly patients. Eur J Anaesthesiol 21: 193-197, 2004.

14. Schug SA, Buerkle H, Moharib M and Cardwell HM: New drugs for neuraxial blockade. Curr Opin Anaesthiol 12: 551-557, 1999.

15. Kotilainen E, Muittari P and Kirvel O: Intradiscal glycerol or bupivacaine in the treatment of low back pain. Acta Neurochir (Wien) 139: 541-545, 1997.

16. Sice PJ, Chan D and MacIntyre PA: Epidural analgesia after spinal surgery via intervertebral foramen. Br J Anaesth 94: 378-380, 2005.

17. Morgan GE, Mikhail MS and Murray MJ (eds): Local anesthetics. In: Clinical Anesthesiology. 4th edition. McGraw-Hill, New York, NY, pp263-275, 2006.

18. McClure JH: Ropivacaine. Br J Anaesth 76: 300-307, 1996.

19. Burlacu CL and Buggy DJ: Update on local anaesthetics: Focus on levobupivacaine. Ther Clin Risk Manage 4: 381-392, 2008.

20. Santorsola R, Casati A, Cerchierini E, Moizo E and Fanelli G: Levobupivacaine for peripheral blocks of the lower limb: A clinical comparison with bupivacaine and ropivacaine. Minerva Anestesiol 67 (Suppl 1): S33-S36, 2001 (In Italian).

21. Casati A, Chelly JE, Cerchierini E, Santorsola R, Nobili F, Grispigni C, Di Benedetto P and Torri G: Clinical properties of levobupivacaine or racemic bupivacaine for sciatic nerve block. J Clin Anesth 14: 111-114, 2002.

22. Alley EA, Kopacz DJ, McDonald SB and Liu SS: Hyperbaric spinal levobupivacaine: A comparison to racemic bupivacaine in volunteers. Anesth Analg 94: 194-198, 2002.

23. Glaser C, Marhofer P,Zimpfer G, Heinz MT, Sitzwohl C, Kapral S and Schindler I: Levo-bupivacaine versus racemic bupivacaine for spinal anesthesia. Anesth Analg 94: 194-198, 2002.

24. Casati A, Moizo E, Marchetti C and Vinciguerra F: A prospective, randomized, double-blind comparison of unilateral spinal anesthesia with hyperbaric bupivacaine, ropivacaine, or levobupivacaine for inguinal herniorrhaphy. Anesth Analg 99: 1387-1392, 2004.

25. Casati A, Santorsola R, Aldegheri G, Ravasi F, Fanelli G, Berti M, Fraschini $G$ and Torri G: Intraoperative epidural anesthesia and postoperative analgesia with levobupivacaine for major orthopedic surgery: A doubleblind, randomized comparison of racemic bupivacaine and ropivacaine. J Clin Anesth 15: 126-131, 2003.

26. Peduto VA, Baroncini S, Montanini S, Proietti R, Rosignoli L, Tufano R and Casati A: A prospective, randomized, double blind comparison of epidural levobupivacaine $0.5 \%$ with epidural ropivacaine $0.75 \%$ for lower limb procedures. Eur J Anaesthesiol 20: 979-983, 2003.

27. Ohmura S, Kawada M, Ohta T, Yamamoto K and Kobayashi T: Systemic toxicity and resuscitation in bupivacaine-, levobupivacaine-, or ropivacaine-infused rats. Anesth Analg 93: 743-748, 2001. 
28. Marganella C, Bruno V, Matrisciano F, Reale C, Nicoletti F and Melchiorri D: Comparative effects of levobupivacaine and racemic bupivacaine on excitotoxic neuronal death in culture and N-methyl-D-aspartate-induced seizures in mice. Eur J Pharmacol 518: 111-115, 2005.

29. National Research Council (US) Committee for the Update of the Guide for the Care and Use of Laboratory Animals. 8th edition, National Academies Press, Washington DC, USA, 2011.

30. Westin BD, Walker SM, Deumens R, Grafe M and Yaksh TL: Validation of a preclinical spinal safety model: Effects of intrathecal morphine in the neonatal rat. Anesthesiology 113: 183-199, 2010.

31. Hamurtekin E, Fitzsimmons BL, Shubayev VI, Grafe MR Deumens R, Yaksh TL and Walker SM: Evaluation of spinal toxicity and long-term spinal reflex function after intrathecal levobupivaciane in the neonatal rat. Anesthesiology 119: 142-155, 2013.

32. Miller RD and Katzung BG: Local anesthetics. In: Basic and Clinical Pharmacology. Katzung BG (ed). 8th edition. Lange Medical Books/McGraw-Hill, New York, NY, pp436-445, 2001.

33. Takenami T, Wang G, Nara Y, Fukushima S, Yagishita S, Hiruma H, Kawakami T and Okamoto $\mathrm{H}$ : Intrathecally administered ropivacaine is less neurotoxic than procaine, bupivacaine and levobupivacaine in a rat spinal model. Can J Anesth 59: 456-465, 2012.

34. Walker SM and Yaksh TL: Neuraxial analgesia in neonates and infants: A review of clinical and preclinical strategies for the development of safety and efficacy data. Anesth Analg 115: 638-662, 2012

35. Hu D, Hu R and Berde CB: Neurologic evaluation of infant and adult rats before and after sciatic nerve blockade. Anesthesiology 86 957-965, 1997.

36. Kohane D, Sankar W, Shubina M, Hu D, Nader R and Berde C: Sciatic nerve blockade in infant, adolescent and adult rats: A comparison of ropivacaine with bupivacaine. Anesthesiology 89: 1199-1208, 1998.

37. Walker SM, Howard RF, Keay KA and Fitzgerald M: Developmental age influences the effect of epidural dexmedetomidine on inflammatory hyperalgesia in rat pups. Anesthesiology 102: 1226-1234, 2005

38. Sanders RD, Xu J, Shu Y, Fidalgo A, Ma D and Maze M: General anesthetics induce apoptotic neurodegeneration in the neonatal rat spinal cord. Anesth Analg 106: 1708-1711, 2008.

39. Walker SM, Goudas LC, Cousins MJ and Carr DB: Combination spinal analgesic chemotherapy: A systematic review. Anesth Analg 95: 674-715, 2002.

40. Gunter J: Benefit and risks of local anesthetics in infants and children. Paediatr Drugs 4: 649-672, 2002.

41. Ivani G and Mossetti V: Continuous central and perineural infusions for postoperative pain control in children. Curr Opin Anaesthesiol 23: 637-642, 2010.

42. Kathirvel S, Sadhasivam S, Saxena A, Kannar TR and Ganjoo P Effects of intrathecal ketamine added to bupivacaine for spinal anaesthesia. Anaesthesia 55: 899-904, 2000.

43. Gonzales JM, Loeb AL, Reichard PS and Irvine S: Ketamine inhibits glutamate-, N-methyl-D-aspartate- and quisqualate-stimulated cGMP production in cultured cerebral neurons. Anesthesiology 82: 205-213, 1995.
44. Himmelseher S, Pfenninger E and Georgieff M: The effects of ketamine-isomers on neuronal injury and regeneration in rat hippocampal neurons. Anesth Analg 83: 505-512, 1996.

45. Himmelseher S, Pfenninger E, Kochs E and Auchter M: $\mathrm{S}(+)$-ketamine up-regulates neuronal regeneration associated proteins following glutamate injury in cultured rat hippocampal neurons. J Neurosurg Anesthesiol 12: 84-94, 2000.

46. Hudetz JA and Pagel PS: Neuroprotection by Ketamine: A review of the experimental and clinical evidence. J Cardiothorac Vasc Anesth 24: 131-142, 2010.

47. Hansen TG: Ropivacaine: A pharmacological review. Expert Rev Neurother 4: 781-791, 2004.

48. Khezri MB, Ghasemi J and Mohammadi N: Evaluation of the analgesic effect of ketamine as an additive to intrathecal bupivacaine in patients undergoing cesarean section. Acta Anaesthesiol Taiwan 51: 155-160,2013.

49. Xie H, Wang X, Liu G and Wang G: Analgesic effects and pharmacokinetics of a low dose of ketamine preoperatively administered epidurally or intravenously. Clin J Pain 19: 317-322, 2003.

50. Martindale SJ, Dix P and Stoddart PA: Double-blind randomized controlled trial of caudal versus intravenous $\mathrm{S}(+)$-ketamine for supplementation of caudal analgesia in children. Br J Anaesth 92: 344-347, 2004

51. Schnabel A, Poepping DM, Kranke P, Zahn PK and Pogatzki-Zahn EM: Efficacy and adverse effects of ketamine as an additive for paediatric caudal anaesthesia: A quantitative systematic review of randomized clinical trials. Br J Anaesth 107: 601-611, 2011.

52. Vranken JH, Troost D, de Haan P, Pennings FA, van der Vegt MH, Dijkgraaf MG and Hollmann MW: Severe toxic damage to the rabbit spinal cord after intrathecal administration of preservative-free S(+)-ketamine. Anesthesiology 105: 813-818, 2006.

53. Hamers FP, Lankhorst AJ, van Laar TJ, Veldhuis WB and Gispen WH: Automated quantitative gait analysis during overground locomotion in the rat: Its application to spinal cord contusion and transection injuries. J Neurotrauma 18: 187-201, 2001.

54. Kim MH, Jung SY, Shin JD, Lee SH, Park MY, Lee KM, Lee JH, Cho K and Lee W: The comparison of the effects of intravenous ketamine or dexmedetomidine infusion on spinal block with bupivacaine. Korean J Anesthesiol 67: 85-89, 2014.

55. Hidayah MN, Liu CY and Joanna OS: Ketamine and tramadol for the prevention of shivering during spinal anaesthesia. Clin Ter 165: 193-198, 2014.

56. Isik C, Demirhan A, Yetis T, Oktem K, Sarman H, Tekelioglu UY and Duran T: Efficacy of intraarticular application of ketamine or ketamine-levobupivacaine combination on post-operative pain after arthroscopic meniscectomy. Knee Surg Sports Traumatol Arthrosc 23: 2721-2726, 2015. 